\title{
LONG CHAIN 1-ALKYL-3-METHYLIMIDAZOLIUM TETRAFLUOROBORATES AS ELECTROLYTES IN Li-ION BATTERIES
}

\author{
P.GONZALEZ ${ }^{1,2}$, J. J. CORNEJO', J.ORTIZ², J. L. GAUTIER ${ }^{2, *}$ \\ ${ }^{1}$ Programa Sustentabilidad y Medio Ambiente, \\ ${ }^{2}$ Laboratorio de Fisicoquímica y Electroquímica de Sólidos. Departamento de Química de los Materiales, Facultad de Química y Biología, \\ Universidad de Santiago de Chile, USACH, Av. L.B. O'Higgins 3363, Casilla 40, Correo 33, Santiago, Chile \\ (Received: January 22, 2009 - Accepted: May 10, 2010)
}

\begin{abstract}
We have determined the electrochemical behavior of a series of long chain 1-alkyl-3-methylimidazolium ionic liquids $\left[\left(\mathrm{R}_{-} \mathrm{mim}\right) \mathrm{BF} \mathrm{F}_{4}\right]$, with alkyl groups ranging from pentyl to octyl, and tested them as electrolytes in lithium ion batteries. These ionic liquids present good conductivities and electrochemical windows which make them likely solvents of choice for $\mathrm{Li}$-ion batteries using $\mathrm{LiMn}_{2} \mathrm{O}_{4}$ as the cathode. Charge/discharge properties of a Li/ $\mathrm{R}-\mathrm{mim}_{\mathrm{B}} \mathrm{BF} / \mathrm{LiMn} \mathrm{O}_{4}$ cell have been evaluated both with the IL as the sole electrolyte and with IL and conducting support. The Li- ion insertion results in IL can be explained on the basis of self aggregation of each long chain 1-alkyl-3-methylimidazolium cation.
\end{abstract}

\section{INTRODUCTION}

It is well known that progress in lithium-ion batteries relies much on improvements in the electrolyte. Ionic liquids (IL) have become a viable alternative as electrolytes for these devices [1]. In general, the most common electrolytes for Li-ion batteries are a mixture of 1:1 EC/EMC (ethylene carbonate and ethyl methyl carbonate) and $\mathrm{LiPF}_{6}$ as conducting salt $[2,3]$.

Ionic liquids made out of 1-alkyl-3-methylimidazolium cations and nonnucleophilic anions such as tetrafluoroborate and hexafluorophosphate are well known. Studies show that IL of this type having alkyl chain lengths ranging from two to five carbons present good conductivity and fair electrochemical windows [4]. On the other hand, it has been emphasized the advantages of small chain IL derived from 1-methylimidazole since they have shown electrochemical windows of $4 \mathrm{~V}$ and more, high ionic conductivity, good solvent capabilities, and good thermodynamic stability [5-7]. However, some difficulties have become evident recently in charge-discharge performance of Li-ion batteries with IL as electrolytes mainly due to passivation of the electrodes, ineffective voltammetric cycling or the need of special additives that enhance reversibility $[8,9]$.

In this work an evaluation of the electrochemical properties and the performance of the long chain $\left[(\mathrm{R}-\mathrm{mim}) \mathrm{BF}_{4}\right]$ series, with $\mathrm{R}=$ pentyl, hexyl, heptyl and octyl, in Li-ion batteries are reported for the first time.

\section{EXPERIMENTAL}

2.1. Reagents and materials

All reagents, 1-methylimidazole, alkyl bromides, and sodium tetrafluoroborate were of analytical grade from Aldrich and were used without further treatment. Chromatographic grade chloroform and analytical grade dichloromethane were used as received from Aldrich. TLC and column chromatography used silica gel from Merck. The ${ }^{1} \mathrm{H}$ spectra $\left(\mathrm{CDCl}_{3}\right.$, Aldrich) of the IL were carried out in a $400 \mathrm{MHz}$ Bruker spectrometer, using the chemical shift of ${ }^{1} \mathrm{H}$ in $\mathrm{CDCl}_{3}$ as the reference.

For the batteries we used metallic lithium as anode $(99 \%, 12.7 \mathrm{~mm}$ diameter rods), $\mathrm{LiMn}_{2} \mathrm{O}_{4}$ from Merck as cathode and $\mathrm{LiBF}_{4}$ from Aldrich. Liquid Teflon ${ }^{\mathrm{TM}}$ and carbon black were obtained from Gulf Co.

2.2. Synthesis of 1-alkyl-3-methylimidazolium tetrafluoroborates.

Step 1. 1-R-3-methylimidazolium bromide: Each member of the series, [R-mim] $\mathrm{Br}(\mathrm{R}=$ hexyl, heptyl and octyl), was prepared from 1-methylimidazole and the proper alkyl bromide in a 1 to 1.1 molar ratio. The excess bromoalkane was taken up in n-hexane to facilitate its separation from the 1-alkyl-3-methyl imidazolium bromide which in turn was used without further treatment in the next step.

Step 2. 1-R-3-methylimidazolium tetrafluoroborate: The metathesis was carried out at room temperature (RT) with stoichiometric amounts of each bromide and sodium tetrafluoroborate dissolved in about $3 \mathrm{~mL}$ of water The resulting IL was separated using dichloromethane extraction and then purified using column chromatography (silica, chloroform elution) with TLC monitoring (silica gel, chloroform). The purified product appeared as a viscous, yellowish oil and was characterized by ${ }^{1} \mathrm{H}$ NMR.

\subsection{Electrochemical measurements}

Conductivity. The conductivity of 1-alkyl-3-methyl-imidazolium tetrafluoroborates $\left[(\mathrm{R}-\mathrm{mim}) \mathrm{BF}_{4}\right]$ was determined in a Oakton Co. $110 \mathrm{AC}$ conductimeter at RT. To ensure a stationary state, each value was obtained after $20 \mathrm{~min}$.

Cyclic voltammetry. We used a small cell designed by us $(5 \mathrm{~mL})$ where the electrolyte was placed (the IL itself), a platinum rotating disk electrode $(2 \mathrm{~mm}$ diameter, $1000 \mathrm{rpm}$ ), and platinum wire as auxiliary electrode. As reference electrode, $\mathrm{Hg} / \mathrm{Hg}_{2} \mathrm{SO}_{4}, \mathrm{~K}_{2} \mathrm{SO}_{4}$ (MSE) was used . For the battery tests, the $\mathrm{Pt}$ electrode was replaced by $\mathrm{LiMn}_{2} \mathrm{O}_{4}$ spinel immersed in IL. The scan rate was $15 \mathrm{mVs}^{-1}$ during 25 cycles.

\subsection{Testing of $\left[(R-m i m) B F_{4}\right]$ as electrolytes in lithium ion batteries}

$\mathrm{A} \mathrm{Li} / 0.3 \mathrm{M} \mathrm{LiBF}_{4}$ in $\left[(\mathrm{R}-\mathrm{mim}) \mathrm{BF}_{4}\right] / \mathrm{LiMn}_{2} \mathrm{O}_{4}$ Swagelock $^{\mathrm{TM}}$ type cell [10] was used having round composite pellets of $\mathrm{LiMn}_{2} \mathrm{O}_{4}$, metallic $\mathrm{Li}$ and $0.3 \mathrm{M}$ $\mathrm{LiBF}_{4}$ in IL as supporting electrolyte. The surface of each electrode was $1 \mathrm{~cm}^{2}$. The $\mathrm{LiMn}_{2} \mathrm{O}_{4}$ composite pellet consisted of a mixture of $90 \%(180 \mathrm{mg})$ neat $\mathrm{LiMn}_{2} \mathrm{O}_{4}, 10 \%(20 \mathrm{mg})$ of carbon black as conductivity additive and about $0.60 \mathrm{~mL}$ of liquid Teflon as mechanical additive. The mixture was compressed at 5 ton $\mathrm{cm}^{-2}$ for 90 seconds, and the resulting pellet was dried in an oven at $150^{\circ} \mathrm{C}$ for two hours, and then stored away in a desiccator under Ar. The $\mathrm{Li}$ electrode was obtained from a cylindrical $\mathrm{Li}$ bar which was stored under anhydrous hexane.

For the charge/discharge tests, the cell was connected to a locally designed equipment. From several current values we have selected $\mathrm{j}=0.4 \mathrm{~mA} \mathrm{~cm}-2$ The scans were performed from the open circuit potential (OCP) to $2.0 \mathrm{~V}$ (discharge) and from OCP to $4.5 \mathrm{~V}$ (charge). In order to reach the stationary state (OCP), at the end both processes were separated by a relaxation time.

\section{RESULTS AND DISCUSSION}

3.1.-Improved synthesis of 1-alkyl-3-methylimidazolium tetrafluoroborates We were able to optimize the synthesis method proposed by Holbrey and Seddon [11]. In step 1, a complete reaction was achieved in $1 \mathrm{~h}$ with $>99 \%$ overall yield for the whole series of bromides. In step 2 a $20 \%$ molar excess of aqueous sodium tetrafluoroborate at RT led to instant reaction and yields of the imidazolium tetrafluoroborates higher than $85 \%$ for all members of the series. These yields are superior to those reported by Holbrey and Seddon, and also by Huddleston [12]. The ${ }^{1} \mathrm{H}$ NMR spectra are in good agreement with data reported for $\left[(\mathrm{R}-\mathrm{mim}) \mathrm{BF}_{4}\right][11]$.

3.2.-Electrochemical properties of $\left[\left(R-\right.\right.$ mim) $\left.B F_{4}\right]$ with $R=$ pentyl, hexyl, heptyl, octyl.

a) Conductivity. Table 1 shows our IL and literature data on small chain IL. 
Table 1. Ionic conductivity of a series of 1-alkyl-3-methylimidazolium tetrafluoroborates, [(R-mim)BF4].

\begin{tabular}{|c|c|}
\hline IL & Conductivity $25^{\circ} \mathrm{C}, \mathrm{mS} \mathrm{cm}^{-1}$ \\
\hline$\left[(\right.$ Ethyl-mim $\left.) \mathrm{BF}_{4}\right]$ & $14.0^{*}$ \\
\hline [(Propyl-mim $\left.) \mathrm{BF}_{4}\right]$ & $5.9^{*}$ \\
\hline$\left[(\right.$ Butyl-mim $\left.) \mathrm{BF}_{4}\right]$ & $3.5^{*}$ \\
\hline$\left[(\right.$ Pentyl-mim $\left.) \mathrm{BF}_{4}\right]$ & $4.4^{* *}$ \\
\hline$\left[(\right.$ Hexyl-mim $\left.) \mathrm{BF}_{4}\right]$ & $5.1 * *$ \\
\hline$\left[(\right.$ Heptyl-mim $\left.) \mathrm{BF}_{4}\right]$ & $4.6^{* *}$ \\
\hline$\left[(\right.$ Octyl-mim $\left.) \mathrm{BF}_{4}\right]$ & $4.6^{* *}$ \\
\hline
\end{tabular}

*ref [4] **this work.

It is widely accepted that the conductivities of imidazolium-type IL depend on their viscosity and the size of the ions involved. According to Nishida [4], an increase in viscosity leads to a decrease in conductivity as the IL chain length increases. Our results with $\mathrm{R}=$ pentyl, hexyl, heptyl, octyl do not follow Nishida's prediction. Indeed, the conductivities shown by the IL in this work appear more than adequate to justify testing them as electrolytes in Li-ion batteries. These unique electrochemical properties can be explained on the basis of recent discoveries that show that imidazolium-type IL with long alkyl chains can form organized assemblies $[13,14]$ which comprise rather complex morphologies [15-20] arising from the nanoscale segregation of the alkyl chains [21-22], thus determining one common attribute for these IL: they facilitate ionic mobility.

b) Electrochemical window.

Using Pt as the working electrode, Fig 1a shows the cyclic voltammetry behavior of IL whereas Fig $1 \mathrm{~b}$ shows their behavior using $\mathrm{LiMn}_{2} \mathrm{O}_{4}$.

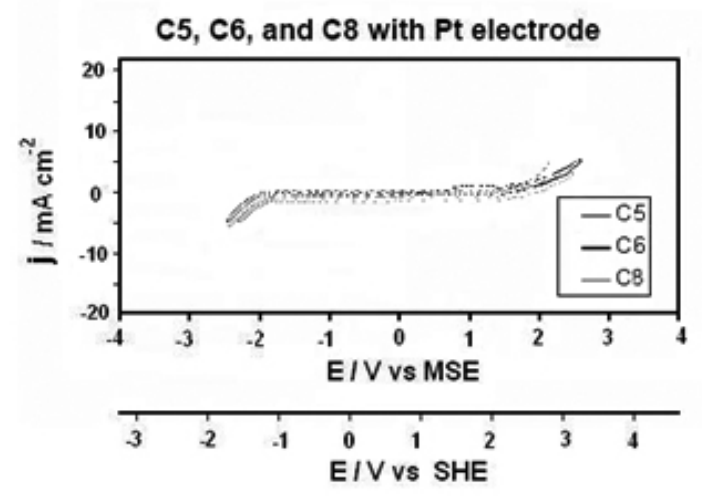

a

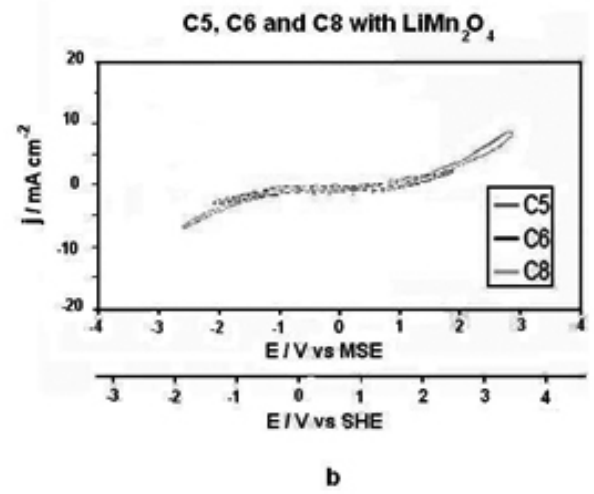

Figure. 1: Cyclic Voltammetry of [(pentyl-mim) $\left.\mathrm{BF}_{4}\right]$, [(hexyl-mim) $\left.\mathrm{BF}_{4}\right]$ and [(octyl-mim) $\left.\mathrm{BF}_{4}\right]$ on a a)Pt electrode and on b) spinel electrode (MSE as reference electrode, scan rate $15 \mathrm{mV} \mathrm{s}^{-1}$ ).
The IL showed good stability, with electrochemical windows of $4.0 \mathrm{~V}$, $4.4 \mathrm{~V}$ and $4.4 \mathrm{~V}$, respectively, for [(pentyl-mim) $\left.\mathrm{BF}_{4}\right]$, [(hexyl-mim) $\left.\mathrm{BF}_{4}\right]$ and [(octyl-mim) $\mathrm{BF}_{4}$. Taken together

with the conductivity outcomes, these results appeared promising in regards to the application of these long chain IL as electrolytes in lithium ion batteries. In fact, in $\mathrm{CV}$ experiments where a spinel electrode was used no currents were detected from insertion or deinsertion processes.

3.3.- Testing of $\left[(R-m i m) B F_{4}\right]$ as electrolytes in lithium ion batteries.

The $\mathrm{Li}^{+}$insertion and $\mathrm{Li}^{+}$deinsertion processes using the $\mathrm{LiMn}_{2} \mathrm{O}_{4}$ electrode correspond to a reduction reaction and an oxidation reaction, respectively, according to :

$$
\begin{aligned}
& \mathrm{LiMn}_{2} \mathrm{O}_{4}+\mathrm{xLi}^{+}+\mathrm{xe}^{-} \\
& \mathrm{LiMn}_{2} \mathrm{O}_{4} \longrightarrow \mathrm{xLi}^{+}+\mathrm{Li}_{1-\mathrm{x}} \mathrm{Li}_{1+x} \mathrm{Mn}_{2}+\mathrm{On}_{4}
\end{aligned}
$$

The insertion degree $\mathrm{x}$ is generally calculated using Faraday's law. The electrode's specific capacity $\left(\mathrm{mAh} \mathrm{g}^{-1}\right)$ is obtained from the theoretical capacity of $\mathrm{LiMn}_{2} \mathrm{O}_{4}(\mathrm{x}=1), 148.2 \mathrm{mAh} \mathrm{g}^{-1}$, by $(1-\mathrm{x})$.

Fig. 2 compares the first charge/discharge curves obtained with 1-hexyl3-methylimidazole tetrafluoroborate and 1-octyl-3-methylimidazole tetrafluoroborate as electrolytes in the cell: $\mathrm{Li} / 0.3 \mathrm{M} \mathrm{LiBF}_{4}$ in $\left[(\mathrm{R}-\mathrm{mim}) \mathrm{BF}_{4}\right]$ / $\mathrm{LiMn}_{2} \mathrm{O}_{4}$. It can be seen that both the insertion and desinsertion reactions take place within -1 and 1 V/SHE where no electrolyte oxidation occurs (see Fig 1).

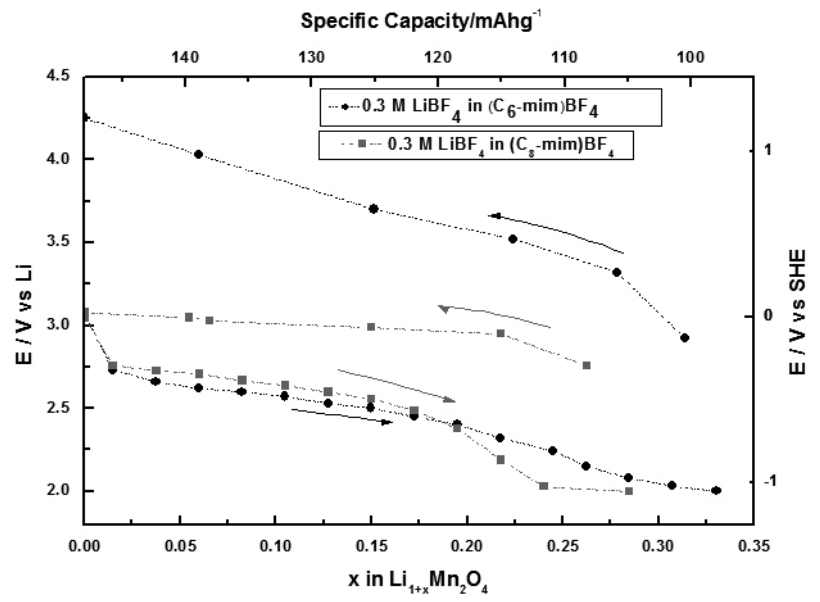

Figure. 2: Comparison $\left[(\right.$ hexyl-mim $\left.) \mathrm{BF}_{4}\right]$ vs. $\left[(\right.$ octyl-mim $\left.) \mathrm{BF}_{4}\right]$ in charge/ discharge assays in a lithium battery system. $\mathrm{j}=0.4 \mathrm{~mA} \mathrm{~cm}{ }^{-2}$.

The charge and discharge capacities appear to be different for both electrolyte systems. The battery with $\left[(\right.$ hexyl-mim $\left.) \mathrm{BF}_{4}\right]$ performs better than that with [(octyl-mim)BF $]$ because the discharge time is longer. On the other hand, the value of the charge potential is higher in the hexyl compound than in the octyl. The battery with $\left[(\right.$ octyl-mim $\left.) \mathrm{BF}_{4}\right]$ does not reach the maximum possible potential in the charge process presumably because the deinsertion of $\mathrm{Li}$ ions from the cathode is more sensitive to having a longer chain that increases viscosity and thus determines a relatively lower conductivity.

In order to verify cell stability, the complete charge/discharge cycles were carried out using the system Li/ $0.3 \mathrm{M} \mathrm{LiBF}_{4}$ in $\left(\mathrm{C}_{6}-\mathrm{mim}\right) \mathrm{BF}_{4} / \mathrm{LiMn}_{2} \mathrm{O}_{4}$. Figure 3 registers the situation in which the 25 th cycle started with the deinsertion of $\mathrm{Li}$ (charge) from the OCP up to $\mathrm{E}=4.5 \mathrm{~V}$ vs Li. Then, a period of relaxation occurs where the $\mathrm{OCP}$ is obtained. The discharge occurs from the $\mathrm{OCP}$ to $\mathrm{E}=$ $2 \mathrm{~V}$ vs Li. The 26th charge-discharge cycle is also showed. A decrease in the specific capacity with the cycling as well as a reduction in the charge maximum potential value and the OCP value are observed. This capacity fading does not appear to be inherent to the electrolyte but rather to the constituent material of the cathode. It is well known that $\mathrm{LiMn}_{2} \mathrm{O}_{4}$ electrode loses capacity as the number of cycles increases in the charge-discharge $[23,24]$. 


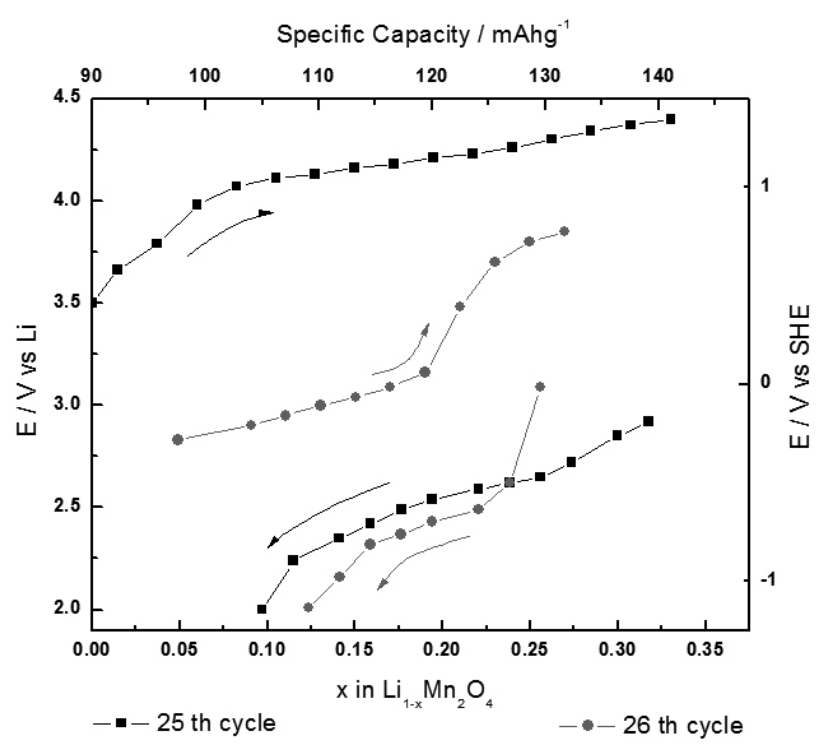

Figure. 3: Charge and discharge test for the system $\mathrm{Li} / \mathrm{LiBF}_{4}$ in $0.3 \mathrm{M}$ $\left(\mathrm{C}_{6}-\mathrm{mim}\right) \mathrm{BF}_{4} / \mathrm{LiMn}_{2} \mathrm{O}_{4}$. Current density , $\mathrm{j}=0.4 \mathrm{~mA} \mathrm{~cm}{ }^{-2}$.

At this point, it was of interest to test the ability of the IL alone to sustain the electrochemical processes of a lithium ion battery.

Fig. 4 displays a comparison between using [(hexyl-mim)BF4] with and without background salt $\mathrm{LiBF}_{4}$. Clearly the addition of lithium salt increases the charge potential limit of the battery. This can be due in part to the selfdiffusion coefficients of ions in the $\mathrm{LiBF}_{4}$ solutions in IL, compared to those in the neat IL as has been proposed by Hayamizu et al.[25].

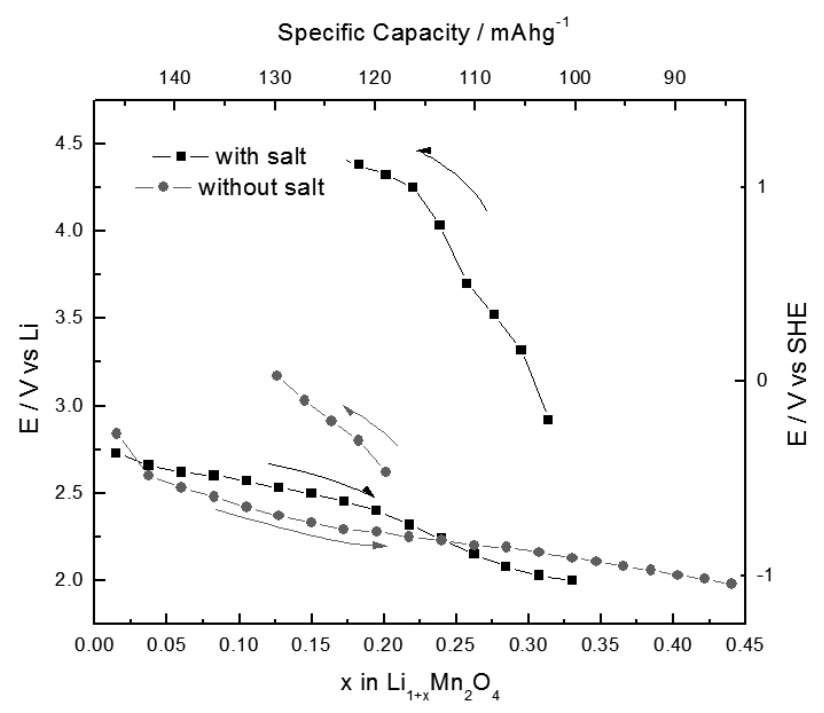

Figure. 4: Testing neat IL as the solvent in $\mathrm{Li}$ ion batteries: Comparison of $\mathrm{Li} / /$ (hexyl-mim) $\mathrm{BF}_{4} / / \mathrm{LiMn}_{2} \mathrm{O}_{4}$ and $\mathrm{Li} / / 0.3 \mathrm{M} \mathrm{LiBF}_{4}$ in [(hexyl-mim) $\left.\mathrm{BF}_{4}\right]$ $/ / \mathrm{LiMn}_{2} \mathrm{O}_{4} \cdot \mathrm{j}=0.4 \mathrm{~mA} \mathrm{~cm}^{-2}$.

It is remarkable that the cell that used just the neat IL as the solvent reached a potential of $3.2 \mathrm{~V}$, which is fairly high upon comparison with the maximum obtained with IL plus lithium salt. This suggests that, pending further studies, a neat, long chain IL bears the potential of becoming the solvent of choice since it can sustain, albeit not completely, the electrochemical processes of a lithium ion battery. This phenomenon together with the fair conductivity presented by these IL, can be rationalized on the basis of the long alkyl chains inducing the formation of organized nanostructures in the 1-alkylimidazolium IL that facilitate Li ion mobility both in the bulk of the system and at the electrode interface during deinsertion. In fact, Padua et al. [18] found out that for IL in the 1-alkyl-3-methylimidazolium series the polar domain has the structure of a tridimensional network of ionic channels, whereas the nonpolar domain is arranged as a dispersed microphase for ethylmethylimidazolium IL and as a continuous one for longer side-chains, such as hexyl, octyl, or dodecyl. With similar arguments Watanabe et al. [20] explain the break in the trends of properties such as viscosity, diffusion coefficient and ionic conductivity that they observed between 1-alkyl-3-methylimidazolium IL with alkyl= methyl or ethyl from those having alkyl= butyl, hexyl or octyl, because only the longest alkyl chains lead to the nanostructures. Moreover, Triolo et al. [21,22] have provided direct experimental evidence of the existence of these microdomains in middle to large size chain (C4 to C10) alkylimidazolium IL, which supports our view that the increased ionic mobility in our IL comes from self aggregation due to the amphiphilic nature of the long chain imidazolium cations which in turn explains the unexpected good performance of 1-hexyl- and 1-octyl3-methylimidazolium tetrafluoroborates when used as electrolytes in Li-ion batteries. This evidence had been advanced earlier by Dupont [26] showing that pure 1,3-dialkylimidazolium ionic liquids follow a structural trend for both the solid and the liquid phase that consists of hydrogen-bonded polymeric supramolecules, a network which is disrupted in the presence of other molecules or ions, and if the imidazolium cation has a fairly long hydrocarbon chain nanostructures with polar and non-polar regions can be formed which can "channel" the transport of mobile species such as metallic ions. However, further work is being contemplated concentrating on the nature of the solid electrolyte interface facing the long chain IL, as well as the characteristics of the insertion/deinsertion processes.

\section{CONCLUSIONS}

Long chain ionic liquids of the type 1-alkyl-3-methylimidazolium tetrafluoroborates can be efficiently prepared with purities suitable for electrochemical applications. These ionic liquids, with alkyl groups ranging from pentyl to octyl, present good conductivities and electrochemical windows which make them likely solvents of choice for Li-ion batteries. The most remarkable result is that each long chain, imidazolium type ionic liquid by itself, that is, with no salt added, can fairly sustain the electrochemical requirements of lithium ion insertion. These results are additional evidence in support of the existence of self aggregation of long chain 1-alkylimidazolium cations, a phenomenon that facilitates ionic conductivity and insertion/deinsertion of $\mathrm{Li}^{+}$.

\section{ACKNOWLEDGEMENTS}

This work was supported by DICYT-USACH (Project 01-0142CP) and FONDECYT (project 1050178).

\section{REFERENCES}

1. D-W Kim, S.R. Sivakkumar, D.R. MacFarlane, M. Forsyth, Y-K Sun, J.Power Sources 180, 591,(2008)

2. D. Aurbach, J.S. Gnarac, W. Geissler, M. Schmidt. J. Electrochemistry Soc. 151, A23,(2004)

3. S. S-Zhang, T.R. Jow, K. Anime, G.L Henriksen. J. Power Sources $\mathbf{1 0 7 , 1 8 , ( 2 0 0 2 )}$

4. T. Nishida, Y. Tashiro, M. Yamamoto, J. Fluorine Chem. 120,135, (2003)

5. T. Prem Kumar, P.G. Balakrishnan, R. Ramesh, J. Power Sources 155,401,(2006)

6. D. Aurbach, V. Baranchugov, E. Markevich, Electrochem. Comm. 8,1331,(2006)

7. G. Cheruvally, J. Kim, J. Ahn. J. Power Sources 172,863,(2007)

8. E. Markevich, V. Baranguchov, G. Salitra, D. Aurbach, M.A Schmidt, J.Electrochem. Soc. 155,A132,(2008)

9. T.Sugimoto, M. Kikuta, E. Ishiko, M. Kono, M. Ishikawa, J. Power Sources 183,436,(2008)

10. D. Guyomard and J.M. Tarascon. J. Electrochem. Soc. 139,937,(1992)

11. J.D. Holbrey and K.R. Seddon, J. Chem. Soc., Dalton Trans. (1999)2133

12. F. Huddleston, Green Chemistry 3(2001)156

13. T. Singh, A. Kumar, J. Phys. Chem. B 111,7843,(2007)

14. T. Singh, A. Kumar. Colloids and Surfaces A: Physicochem. Eng. Aspects 318, 263,(2008)

15. J. Wang, H. Wang, S. Zhang, H. Zhang, Y. Zhao, J. Phys. Chem. B 111, 6181,(2007),

16. S.M. Urahata, M.C.C. Ribeiro, J. Chem. Phys. 120 1855(2004)

17. Y. Wang, G.A. Voth, J. Am. Chem. Soc. 12712192(2005)

18. J.N.A. Canongia Lopes, A.A.H. Padua, J. Phys. Chem. B 110,3330,(2006) 
19. Y. Wang, G.A. Voth, J. Phys. Chem. B 110, 18601,(2006)

20. H.Tokuda, K. Hayamizu, K. Ishii, H. Susan, M. Watanabe. J. Phys. Chem. B 109, 6103,(2005)

21. A. Triolo, O. Russina, H.J. Bleif, E. Di Cola, J. Phys. Chem. B 111, 4641,(2007)

22. A. Triolo, O. Russina, B. Fazio, R. Triolo, E. Di Cola. Chem.Phys.Lett. 457,362, (2008)
23. J.W. Fergus, J. Power Sources 195, 939,(2010)

24. B. Scrosati, J. Garche, J.Power Sources 195,2419, (2010)

25. K. Hayamizu, Y. Aihara, H. Nakagawa, T. Nukuda, W.S. Price, J. Phys. Chem B 108, 19527,(2004)

26. J. Dupont, J. Braz. Chem. Soc. 15, 341,(2004). 